Original Article

\title{
SYNTHESIS OF BIS-BENZIMIDAZOLES N-ALKYL ANTI-INFECTIOUS DERIVATES
}

\author{
AKPA SAGNE JACQUES ${ }^{*}{ }^{*}$, DIOMANDE GBE GONDO DIDIER¹, ZON DOUMADE², ADJOU ANE1
}

${ }^{1}$ Laboratoire de Constitution et Reaction de la Matiere (LCRM). Université Felix Houphouet-Boigny Abidjan-Cocody-22 BP 582 Abidjan 22 Cote d'Ivoire, '2Departement de Biochimie Genetique, UFR Sciences Biologiques, Universite Gon Coulibaly-BP 1328 Korhogo-Côte-d'Ivoire Email: sagnbest@yahoo.fr

Received: 19 Nov 2020, Revised and Accepted: 21 Apr 2021

\section{ABSTRACT}

Objective: The objective of this work is to synthesize new molecules with biological characteristics against some infectious germs.

Methods: The method of synthesis is based on the exploitation of the reactivity of the position-1 of the benzimidazole. It consisted of reacting the bis-benzimidazole 5 with the 1,2-dicloroethane in a solution of $\mathrm{NaOH} 2 \mathrm{~N}(6,4 \%)$. The compound 6 is refluxed with ethanol with the different thioaryls to lead to compounds 7.

Results: Thus, a series of molecules derived from bis-benzimidazoles were synthesized including $N$-alkylated 6 and 7 a-d. The characterization of these newly synthesized compounds was performed by NMR $\left({ }^{1} \mathrm{H}\right.$ and $\left.{ }^{13} \mathrm{C}\right)$ and mass spectroscopy methods.

Conclusion: The purified and characterized compounds 6 and $7 \mathrm{a}$-d allow the development of a new chemical class of anti-infectives.

Keywords: 2-thiomethylbenzimidazolylbenzothiazole, Benzimidazole anologues and, Bis-benzimidazoles

(C) 2021 The Authors. Published by Innovare Academic Sciences Pvt Ltd. This is an open access article under the CC BY license (https://creativecommons.org/licenses/by/4.0// DOI: https://dx.doi.org/10.22159/ijpps.2021v13i6.40310. Journal homepage: https://innovareacademics.in/journals/index.php/ijpps .

\section{INTRODUCTION}

Benzimidazole, as a result of the replacement of the imidazole nucleus by other pentagonal heterocycles, notably thiazole and oxazole, leads respectively to the analogues benzothiazoles [1] and benzoxazoles [2]. Currently, the fight against certain infectious diseases is based on the use of molecules containing in their skeleton the benzothiazole rings and its analogues. We will mention among others: Riluzole used to treat amyotrophic lateral sclerosis [3], albendazole [4], used to eliminate gastrointestinal parasites, chlormidazole in therapeutics as the first antifungal [5-8] and Flunoxaprofen $[9,10]$ for the treatment of cancer (fig. 1). However, their therapeutic efficacy is becoming increasingly limited by the emergence of resistant microbial strains. In this context, it seems crucial to design and prepare new anti-infective agents with potentially better performance. In this perspective, we are interested in the chemical series of 2-thiomethylbenzimidazoles. The objective of this work is to develop new biomolecules likely to fight against certain infectious germs.

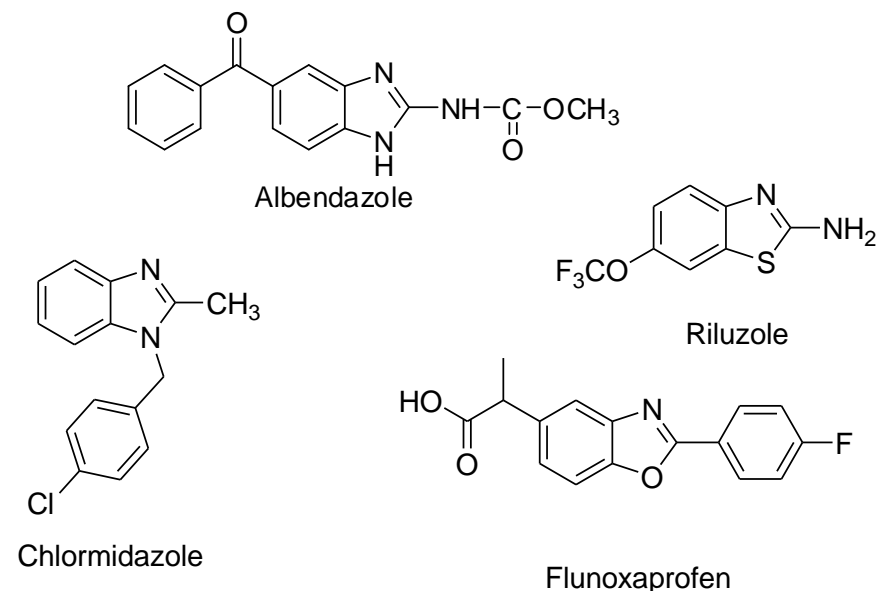

Fig. 1: Commercial molecules against various infections

\section{MATERIALS AND METHODS}

The ${ }^{1} \mathrm{H}$ proton $(300-400 \mathrm{MHz})$ and ${ }^{13} \mathrm{C}$ carbon $(75-100 \mathrm{MHz})$ Nuclear Magnetic Resonance (NMR) spectra were recorded on a Brüker Advance 300, Tetramethylsilane (TMS) is used as an internal reference for chemical shifts expressed in ppm. Mass spectra (MS) were performed on an HP 5889A quadrupole electron impact (IE) or chemical ionization (CI) spectrometer. Melting points were determined by means of a KÖFFLER bench with temperature grading $\left(40-260{ }^{\circ} \mathrm{C}\right)$. Dichloromethane, toluene, ethanol, ethyl acetate and hexane were distilled under atmospheric pressure. The purifications by column chromatography were carried out on silica gel type Kieselgel 60 (230-400 mesh-Merck).

The aim of this work is to synthesize 2-thiomethylbenzimidazolylbenzothiazole derivatives substituted in position 1 of the pyrrolic 
nitrogen. The methodology of the work consisted of condensing a chlorinating agent on heterocyclic and aryl compounds. To achieve these objectives, we initially performed the synthesis of 1-(chloroethyl)-2thiomethylbenzimidazolylbenzothiazole (6). The 2thiomethylbenzimidazolyl-benzothiazole (5) which served as our basic molecule was obtained in $54 \%$ yield by reacting 2mercaptobenzothiozole and 2-chloromethylbenzimidazole in a mixture of $\mathrm{THF} / \mathrm{NEt}_{3}$ (triethylamine/tetrahydrofuran) at room temperature. Then, 1,2-dicloroethane reacted with 2-thiomethyl-benzimidazolylbenzothiazole (5) at $150{ }^{\circ} \mathrm{C}$ in $2 \mathrm{~N} \mathrm{NaOH}(6.4 \%)$, to lead to compound (6) with a $88 \%$ yield. In order to achieve a chain of ethylthioaryl groups, we reacted thioaryls with compound (6) by condensation. Thus, the action of thiophenol on 1-(2-chloroethyl)-2-thiomethylbenzimidazolybenzothiazole (6) in ethanol at reflux gave 1(ethylthiophenyl)-2-thiomethylbenzimidazolylbenzothiazole (7a) in $62 \%$ yield. The action of 2-mercaptobenzimidazole and its analogues on 1-(2-chloroethyl)-2-benzimidazolylbenzothiazole in refluxing ethanol gave 1-(ethylheteroaryl)-2-thiomethylbenzimidazolylbenzothiazole (7bd) in yields between 34 and 65\% (Scheme 1).

\section{2-thiomethylbenzimidazolylbenzothiazole (5)}

In a round bottom flask, a mixture of 2-(chloromethyl)-1Hbenzimidazole $(1.66 \mathrm{~g})$ and 2-mercaptobenzothiazole $(1.51 \mathrm{~g})$ in THF $(30 \mathrm{ml})$ is stirred in the presence of triethylamine $(2 \mathrm{ml})$ for $6 \mathrm{~h}$ at room temperature. Then, THF is removed using a rotary evaporator and ice water $(30 \mathrm{ml})$ is added to the reaction medium to get a precipipate solid. After filtration, the crude solid product is washed with water and purified on silica gel using a mixture of acetone and hexane: (4.25/0.75) as an eluent. Yield $=54 \% ; \mathrm{Mp}=176-177^{\circ} \mathrm{C}$ (hexane $/$ ethyl acetate) NMR ${ }^{1} \mathrm{H}$ (DMSOd-6, $\delta$ ppm): 4,90 (2H, s, SCH2); 7,15-7,19 $\left(2 \mathrm{H}, \mathrm{m}, \mathrm{H}_{\mathrm{ar}}\right.$ ); 7,34-7,59 (4H, m, H); 7,59-7,91 (1H, m, $\left.\mathrm{H}_{\mathrm{ar}}\right) ; 8,01-8,04\left(1 \mathrm{H}, \mathrm{m}, \mathrm{H}_{\mathrm{ar}}\right.$ ); $\mathrm{NMR}^{13} \mathrm{C}$ (DMSOd-6, $\left.\delta \mathrm{ppm}\right): 28,86\left(\mathrm{~S}-\mathrm{CH}_{2}\right) ; 45,5(\mathrm{CH} 2 \mathrm{Cl}) ; 60(\mathrm{~N}-$ CH2);121,56 ( $\left.\mathrm{C}_{\mathrm{ar}}\right), 149,27\left(\mathrm{CH}_{2}-\mathrm{C}=\mathrm{N}\right) ; 150,51(\mathrm{~N}=\mathrm{C}-\mathrm{S}) . \mathrm{SDM}: \mathrm{m} / \mathrm{e}(\%)=$ 132,9 (61); 151 (69); 261,1 (25); 280 (7); 281 (100); 282,1 (20).

\section{1-(2-Chloroethyl)-2-thiomethylbenzimidazolylbenzothiazole (6)}

In a flask, $2 \mathrm{~g}$ ( $1.1 \mathrm{mmol})$ of 2-thiomethylbenzimidazolyl-benzothiazole are dissolved in $40 \mathrm{ml}$ of $2 \mathrm{~N}$ sodium hydroxide solution $(6.4 \%)$. The mixture is stirred for $30 \mathrm{~min}$, then $5 \mathrm{ml}$ of 1,2-dichloroethane and a pinch of tetrabutylammonium (TBA) are added. The mixture is heated at $150{ }^{\circ} \mathrm{C}$ for $1 \mathrm{~h}$. After cooling to room temperature, a $10 \%$ hydrochloric acid solution is added to the reaction medium to get a precipitate which is filtered under filter paper and dried. Yield: 88\%;
$\mathrm{Mp}=132-133^{\circ} \mathrm{C}, \mathrm{NMR}^{1} \mathrm{H}(\mathrm{DMSOd}-6, \delta \mathrm{ppm}): 4,54\left(2 \mathrm{H}, \mathrm{s}, \mathrm{SCH}_{2}\right) ; 4,00$ $\left(2 \mathrm{H}, \mathrm{t}, \mathrm{CH}_{2} \mathrm{~N}\right) ; 3,26(2 \mathrm{H}, \mathrm{t}, \mathrm{CH} 2-\mathrm{S}-\mathrm{Ar}) ; 7,24-8,1$ (m, Har). $\mathrm{NMR}^{13} \mathrm{C}$ (DMSOd-6, $\delta$ ppm): 28,86 (S-CH2); 45,5 (CH2Cl); 60 (N-CH2); 121,56 $\left(\mathrm{C}_{\mathrm{ar}}\right), 149,27\left(\mathrm{CH}_{2}-\mathrm{C}=\mathrm{N}\right) ; 150,51(\mathrm{~N}=\mathrm{C}-\mathrm{S})$.

\section{1-(Ethylheteroaryl)-2-thiomethylbenzimidazolylbenzothiazole (7)}

In a $100 \mathrm{ml}$ flask, $0.3 \mathrm{~g}$ of 1-(2-chloroethyl)-2thiobenzimidazolylbenzothiazole is dissolved in $10 \mathrm{ml}$ of ethanol solution. The mixture is stirred at room temperature for $30 \mathrm{~min}$. Then 1.5 eq of 2-mercaptobenzimidazole or analogues are added. Then the reaction mixture is heated under reflux for $7 \mathrm{~h}$. The reaction mixture is cooled and neutralized with a $5 \%$ sodium hydrogen carbonate $\left(\mathrm{NaHCO}_{3}\right)$ solution. The precipitate obtained is recovered by filtration on filter paper, washed with ethanol and dried.

\section{1-(2-Ethylthiophenyl)-2-thiomethylbenzimidazolyl- benzothiazole (7a)}

Yield $=62 \% ; \mathrm{Mp}=130-131^{\circ} \mathrm{C} . \mathrm{NMR}{ }^{1} \mathrm{H}($ DMSOd-6, $\delta \mathrm{ppm}): 4,54(2 \mathrm{H}$, s, $\left.\mathrm{SCH}_{2}\right) ; 4,00\left(2 \mathrm{H}, \mathrm{t}, \mathrm{CH}_{2} \mathrm{~N}\right) ; 3,26(2 \mathrm{H}, \mathrm{t}, \mathrm{CH} 2-\mathrm{S}-\mathrm{Ar}) ; 7,24-8,1$ (m, Har). NMR ${ }^{13} \mathrm{C}$ (DMSOd-6, $\delta$ ppm): 28,86 $\left(\mathrm{S}-\mathrm{CH}_{2}\right) ; 34,3$ (N-CH2); 51 (CH2-S$\mathrm{Ar}) ; 121,56\left(\mathrm{C}_{\mathrm{ar}}\right), 149,27\left(\mathrm{CH}_{2}-\mathrm{C}=\mathrm{N}\right) ; 150,51(\mathrm{~N}=\mathrm{C}-\mathrm{S})$.

\section{1-(ethylthiobenzimidazolyl)-2-thiomethylbenzimidazolyl benzothiazole ( $7 \mathrm{~b})$}

Yield $=55 \% ; \mathrm{Mp}=239-240{ }^{\circ} \mathrm{C} ; \mathrm{NMR}{ }^{1} \mathrm{H}($ DMSOd- $6, \delta \mathrm{ppm}): 4,54(2 \mathrm{H}$ s, CH2S); 3,40 (2H, t, $\left.\mathrm{CH}_{2} \mathrm{SAr}\right) ; 4,15\left(2 \mathrm{H}, \mathrm{t}, \mathrm{CH}_{2} \mathrm{~N}\right) ; 7,21-8,10$ (m, Har). NMR ${ }^{13} \mathrm{C}$ (DMSOd-6, $\delta$ ppm): 28,86 $\left(\mathrm{S}-\mathrm{CH}_{2}\right) ; 34,6$ (N-CH2); 51 (CH2-SAr); 121,56 ( $\mathrm{Car}), 149,27\left(\mathrm{CH}_{2}-\mathrm{C}=\mathrm{N}\right) ; 150,51(\mathrm{~N}=\mathrm{C}-\mathrm{S})$.

\section{1-(Ethylthiobenzothiazolyl)-2-thiomethylbenzimidazolyl- benzothiazole (7c)}

Yield: $34 \%, \mathrm{Mp}>260^{\circ} \mathrm{NMR}{ }^{1} \mathrm{H}$ (DMSOd-6, $\left.\delta \mathrm{ppm}\right): 4,54(2 \mathrm{H}, \mathrm{s}$, $\mathrm{CH} 2 \mathrm{~S}) ; 3,76$ (2H, t, $\left.\mathrm{CH}_{2} \mathrm{SAr}\right) ; 4,15\left(2 \mathrm{H}, \mathrm{t}, \mathrm{CH}_{2} \mathrm{~N}\right) ; 7,21-8,10$ (m, Har). $\mathrm{RMN}^{13} \mathrm{C}$ (DMSOd-6, $\delta$ ppm): 28,86 $\left(\mathrm{S}^{-} \mathrm{CH}_{2}\right) ; 34,6$ (N-CH2); 51 (CH2-SAr); 121,56 ( $\left.\mathrm{Car}_{\mathrm{ar}}\right), 149,27\left(\mathrm{CH}_{2}-\mathrm{C}=\mathrm{N}\right) ; 150,51(\mathrm{~N}=\mathrm{C}-\mathrm{S})$.

\section{1-(Ethylthiobenzoxazolyl)-2-thiomethylbenzimidazolyl- benzothiazole (7d)}

Yield: $65 \%, \mathrm{Mp}>260{ }^{\circ} \mathrm{C}, \mathrm{NMR}{ }^{1} \mathrm{H}$ (DMSOd-6, $\left.\delta \mathrm{ppm}\right): 4,54(2 \mathrm{H}, \mathrm{s}$, CH2S); 3,40 (2H, t, $\left.\mathrm{CH}_{2} \mathrm{SAr}\right) ; 4,15\left(2 \mathrm{H}, \mathrm{t}, \mathrm{CH}_{2} \mathrm{~N}\right) ; 7,21-8,10$ (m, Har). NMR ${ }^{13} \mathrm{C}$ (DMSOd-6, $\delta$ ppm): 28,86 $\left(\mathrm{S}-\mathrm{CH}_{2}\right) ; 34,6$ (N-CH2); 51 (CH2-S$\mathrm{Ar}) ; 121,56\left(\mathrm{C}_{\mathrm{ar}}\right), 149,27\left(\mathrm{CH}_{2}-\mathrm{C}=\mathrm{N}\right) ; 150,51(\mathrm{~N}=\mathrm{C}-\mathrm{S})$.

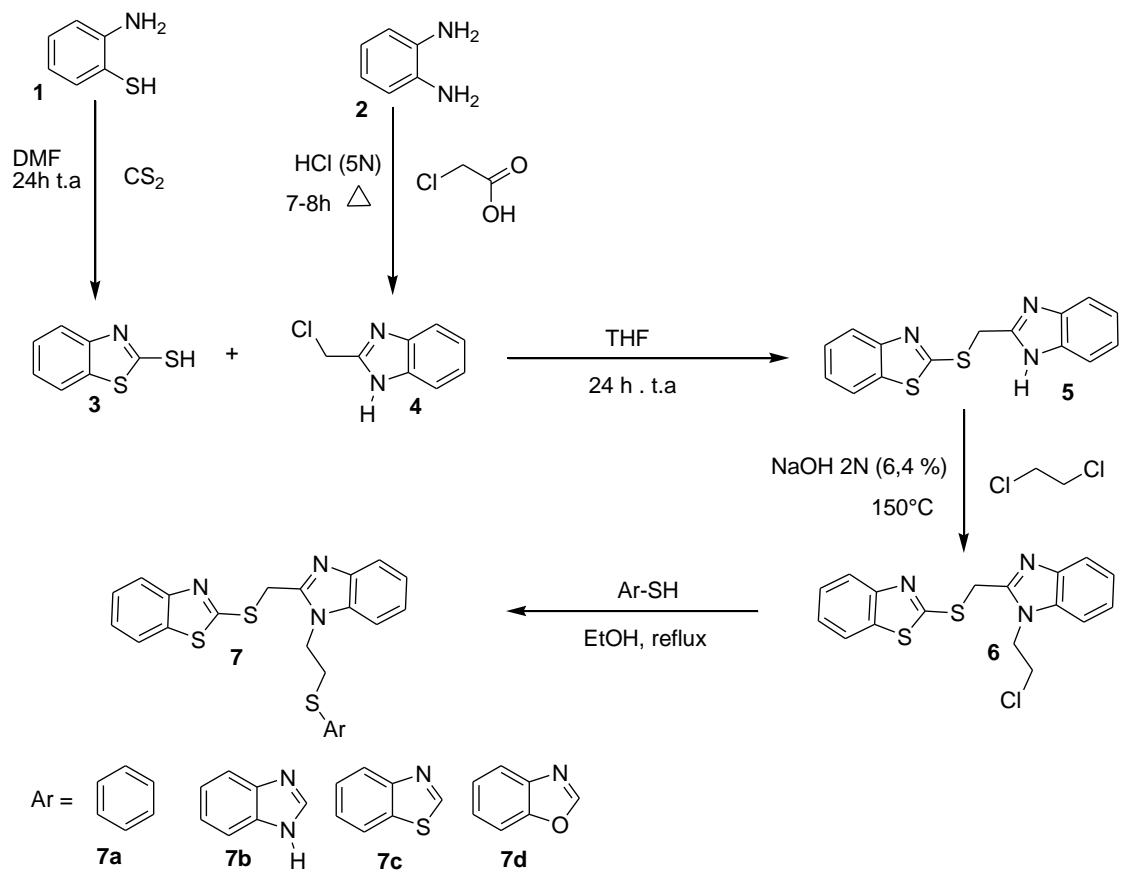

Scheme 1: Synthesis of 2-(2-((benzo[d] oxazol-2-ylthio)methyl)-1H-benzo[d]imidazol-1-yl)acetohydrazide derivatives 


\section{RESULTS AND DISCUSSION}

We have synthesized and characterized 6 derivatives of $N$-alkylated bis-benzimidazoles (5, 6 and 7a-d). These are listed in table 1 with their melting points, reaction yields and spectroscopic data. All compounds have in their respective molecule, the heterocycle benzimidazole and its analog benzothiazole as a basic molecule. Also, these molecules carry on the pyrrolic nitrogen of the benzimidazole nucleus a thioakylaryl linkage. The analysis of the ${ }^{1} \mathrm{H}$ NMR spectrum for compound 5 , base molecule, revealed the presence of a singlet $\delta=4.90 \mathrm{ppm}$ and this peak is attributed to the protons of the methylene group of 2-thiomethylbenzimidazolylbenzothiazole (5). As for the ${ }^{13} \mathrm{C}$ spectrum, we noticed the presence of a signal at $28.86 \mathrm{ppm}$ which characterized the carbon of the (S$\mathrm{CH}_{2}$ ) group. From compound 5, we proceeded to alkylation with 1,2dichloroethane [11], which allowed us to obtain compound 6 . The ${ }^{1} \mathrm{H}$ NMR analysis of 6 revealed the disappearance of the signal of the proton of the pyrrolic nitrogen initially around $12 \mathrm{ppm}$. Also, this analysis indicated the presence of two signals at $3.74 \mathrm{ppm}$ and 4.60 ppm which could be attributed to the two methylenes between nitrogen and sulfur $\left(\mathrm{N}-\mathrm{CH}_{2}-\mathrm{CH}_{2}-\mathrm{S}\right)$. On its ${ }^{13} \mathrm{C}$ NMR spectrum, we observed the remarkable presence of 2 major signals at $45 \mathrm{ppm}$ and $60 \mathrm{ppm}$ which corresponded to the carbon peaks of the $\mathrm{N}-\mathrm{CH}_{2}-\mathrm{CH}_{2}-\mathrm{S}$ group.

Finally, the coupling reaction between compound 6 and the different mercaptobenzimidazoles and its analogues gave compounds $7 \mathrm{a}$ and $7 \mathrm{~b}$-d. In addition to the remarkable peaks on these different ${ }^{1} \mathrm{H}$ and ${ }^{13} \mathrm{C}$ NMR spectra, we noted the massive presence of protons around $7 \mathrm{ppm}$ which corresponded to the peaks of aromatic protons of the aryl and benzimidazole ring. On the ${ }^{13} \mathrm{C}$ spectrum of compound 7 , we had peaks between 115 and 165 ppm which were the aromatic peaks. All this information confirmed the synthesis of compounds 5 6 , and $7 \mathrm{a}-\mathrm{d}$.

Table 1: The physicochemical properties of synthesized bis-benzimidazole $\mathrm{N}$-alkyl derivatives

\begin{tabular}{|c|c|c|c|c|c|}
\hline Comp. & Molecular formula (M. Wt.) & Molecular structure & M. P. $\left({ }^{\circ} \mathrm{C}\right)$ & $\mathrm{R} f$ values & Yield \% \\
\hline 5 & $\begin{array}{l}\mathrm{C}_{15} \mathrm{H}_{11} \mathrm{~N}_{3} \mathrm{~S}_{2} \\
(297,40)\end{array}$ & & $176-177$ & 0,37 & 54 \\
\hline 6 & $\begin{array}{l}\mathrm{C}_{17} \mathrm{H}_{14} \mathrm{ClN}_{3} \mathrm{~S}_{2} \\
(359,90)\end{array}$ & & $132-133$ & 0,66 & 88 \\
\hline $7 a$ & $\begin{array}{l}\mathrm{C}_{23} \mathrm{H}_{19} \mathrm{~N}_{3} \mathrm{~S}_{3} \\
(433.61)\end{array}$ & & $130-131$ & 0,86 & 62 \\
\hline $7 \mathbf{b}$ & $\begin{array}{l}\mathrm{C}_{24} \mathrm{H}_{19} \mathrm{~N}_{5} \mathrm{~S}_{3} \\
(473,08)\end{array}$ & & $239-240$ & 0,4 & 55 \\
\hline 7c & $\begin{array}{l}\mathrm{C}_{24} \mathrm{H}_{18} \mathrm{~N}_{4} \mathrm{~S}_{4} \\
(490,04)\end{array}$ & & $>260$ & 0,74 & 34 \\
\hline $7 d$ & $\begin{array}{l}\mathrm{C}_{24} \mathrm{H}_{18} \mathrm{~N}_{4} \mathrm{OS}_{3} \\
(474,06)\end{array}$ & & $>260$ & 0,43 & 65 \\
\hline
\end{tabular}




\section{CONCLUSION}

The compounds 1-(ethylheteroaryl)-2-thiomethylbenzimidazolylbenzothiazoles $7 \mathrm{a}-\mathrm{d}$ were obtained by a four-step chemical reaction. The yield and purity of these compounds were found to be satisfactory. All these molecules are further aimed to screen suitable pharmacological properties, especially anthelmintic and antifungal.

\section{ACKNOWLEDGEMENT}

Our sincere thanks to the Laboratory of Constitution and Reaction of Matter (LCRM) University Félix Houphouët-Boigny Abidjan and the University of Nantes and Amiens (France) for the spectroscopic analysis.

\section{FUNDING}

\section{Nil}

\section{AUTHORS CONTRIBUTIONS}

All authors had equally contributed the research work

\section{CONFLICT OF INTERESTS}

All authors have none to declare

\section{REFERENCES}

1. Anandarajagopal K, Ravi N Tiwari, KG Bothara, J Anbu Jeba Sunilson, C Dineshkumar, $P$ Promwichit. 2Mercaptobenzimidazole derivatives: synthesis and anticonvulsant activity. Adv Appl Sci Res 2010;1:132-8.

2. Mohammed Afzal Azam, Bhojraj Suresh. Biological activities of 2mercaptobenzothiazole derivatives. Sci Pharm 2012;80:789-823.

3. A Kamal. Synthesis and apoptosis-inducing ability of new anilino substituted pyrimidine sulfonamides as potential anticancer agents. Eur J Med Chem 2011;46:5817-24.
4. A Mahiuddin, David $\mathrm{Cb}$, Naresh K. Synthesis, reactivity and activity benzimidazoles. Topics Heterocyclic Chem 2007;9:87118.

5. Alan R Katritzky, Diana C Aslan, Peter Leeming, Peter J Steel. Asymmetric induction using chiral 1,2,4-triazole and benzimidazole derivatives. Tetrahedron Asymmetry 1997;9:1491-500.

6. Chung Kyu Ryu, Ra-Young Lee, Na Young Kim, Yang Hui Kim, Ae Li Song. Synthesis and antifungal activity of benzo[d]oxazole4,7-diones. Bioorg Med Chem Lett 2009;19:5924-26.

7. Sham M Sondhi, Nirupma Singh, Ashok Kumar, Olivier Lozach Laurent Meijer. Synthesis anti-inflammatory, analgesic and kinase (CDK-1,CDK-5 and GSK-3) inhibition activity evaluation of benzimidazole/benzoxazole derivatives and some Schiff's bases. Bioorg Med Chem Lett 2006;14:3758-65.

8. Nageshwar Rao Chilumula, Dayakar Gadhe, Rajyalaxmi Gudipati, Srinivas Ampati, Sarangapani Manda. Synthesis of some novel methyl-2-(2-(arylideneamino) oxazol-4-ylamino) benzoxazole-5-carboxylate derivatives as antimicrobial agents. Int J Chem Res 2010;1:1-6.

9. Bryson H, B Fulton, P Benfield. Riluzole: a review of its pharmacodynamic and pharmacokinetic properties and therapeutic potential in amyotrophic lateral sclerosis. Drugs 1996;52:549-63.

10. Stefania Aiello, Geoffrey Wells, Erica L Stone, Hachemi Kadri, Rana Bazzi, David R Bell, et al. Synthesis and biological properties of benzothiazole, benzoxazole, and chromen-4-one analogues of the potent antitumor agent 2-(3,4dimethoxyphenyl)-5-fluorobenzothiazole (PMX610, NSC 721648). J Med Chem 2008;51:5135-9.

11. Saloni Kakkar, Sumit Tahlan, Siong Meng Lim, Kalavathy Ramasamy, Vasudevan Mani, Syed Adnan Ali Shah. Benzoxazole derivatives: design, synthesis and biological evaluation. Chem Central J 2018;12:92. 